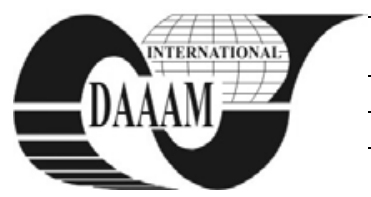

\title{
IMPLICATIONS OF PRICES AND INCOMES UPON THE RESITA POPULATION'S CONSUMPTION
}

\author{
TANASE, A[drian] C[ostinel]; DINU, G[abriel]; TANASE, F[lorenta] D[iana] \& DINU, L[oredana]
}

\begin{abstract}
The economic theory of consumption, whose bases were put, especially, by Ernest Engel (1821-1896) through the theory of demand, has been substantially enriched along time through contributions of modern and post-modern economists. Nevertheless, through its vast thematics, the study of the patterns of the population's consumption still remains a field to exploit. Starting from these considerations, the paper aims at identifying the impact of prices and incomes upon the Reşiţa population's consumption. In this respect, in the research performed one used structured individual inquiries, based on a questionnaire.
\end{abstract}

Key words: prices, incomes, consumption, needs

\section{INTRODUCTION}

Along with the development of society, consumption has exhibited an increasingly high importance for the national and international economy, raising at the same time numerous problems, both as regards the manner of its satisfaction and in relation with the follow-up, analysis, quantification and prediction of its main modalities of achievement (Cismaş, 2004).

Aiming at satisfying the population's material and spiritual needs, consumption has witnessed an ascendant evolution in time, as a result of the increase and diversification of needs, but also of the increasingly wider possibilities of society to satisfy them; along with the qualitative growth, consumption has also undergone a series of structural mutations, triggered by the process of demand hierarchisation and the level and rhythms of economic and social development (Cătoiu et al., 2002).

Nevertheless without reducing the importance of the other factors contributing to the modelling of the consumer behaviour, we must accept that economic factors - and especially prices and incomes - are likely to have the strongest influence on the dynamics and structure of consumption, especially in societies characterised by a low living standard.

\section{GENERAL PRESENTATION OF THE RESEARCH}

At present, the research of the consumer behaviour is done with the help of the motivational research, and is focused on those aspects of the consumer behaviour that are considered to be the most relevant (Stanciu, 2006).

Lacking sufficient or highly representative statistic data necessary for formulating conclusions regarding the influences exercised by prices and incomes on the Reşiţa consumers' behaviour, we realised for this purpose a direct research among the population (Reşiţa is a town in South West Romania).

As for the sampling method, we used the method of shares, i.e. a rational selection of individuals, aiming at obtaining, at the level of the sample, a structure by genders, age groups and socio-professional categories identical with the structure of the Reşiţa town's population.
In the case of the present research, taking into consideration its goal, we considered it opportune to perform a quantitative survey (on a sample made of 1308 persons), whereas as regards the manner of deploying the investigation we decided on an occasional inquiry.

\section{INTERPRETATION OF THE SURVEY RESULTS}

1. The position of the subjects towards the structure of the expenditure effected.

A share of $39.53 \%$ ( $47.86 \%$ of men and $31.76 \%$ of women) of the total interviewed persons declare that the largest share of their expenditures is allotted for the purchase of food products. The highest share is registered in the case of people aged 60 and more (62.69\%), i.e. especially pensioners.

On the other hand, the lowest percentages were registered by those who declare to allot the largest share of their expenses for household and home appliances and products - $5.66 \%$ (3.80\% of men and $7.39 \%$ of women).

We must point out that $23.01 \%$ of the interviewed subjects spend more for services, whereas $16.74 \%$ reserve the largest share of their expenditure to clothes and shoes, and $15.06 \%$ spend more for cosmetics.

2. The attitude of the subjects towards the level of the products' prices.

Most subjects $-65.98 \%$ (68.78\% men and $63.37 \%$ women) consider the prices of products as being high, this opinion being found especially among the people aged 60 and more (2,69\%), i.e. especially the retired persons.

At the opposite pole, the lowest percentages - 3.82\% (4.44\% men and $3.25 \%$ women) are represented by those who consider the prices of goods as being accessible, the lowest weights being registered in this case also by the people aged 60 and above, thus by pensioners (2.07\%).

We should underline the fact that $14.76 \%$ consider that the prices of products are very high, and $15.44 \%$ think that the prices are medium.

3. The position of the subjects in relation with the importance of prices in the purchase decision-making in the case of current food products.

Almost two thirds of those interviewed - 64.98\% (68.78\% of men and $61.44 \%$ of women) declare that for them, in this case, the price has a rather reduced importance, as these products must be bought anyway. This idea is expressed especially by those aged 20 and below, i.e. by pupils and students (69.30\%), with the mention that the other categories of consumers also registered very high weights, reaching even $79.79 \%$ in the case of intellectuals.

Only $16.21 \%$ (14.74\% men and $17.59 \%$ women) affirm that the price is the essential element when they make the purchase decision also in the case of current food products, the lowest percentages being registered in this case too among those under 20 , i.e. pupils and students $(10.13 \%)$.

We should remark that $18.81 \%$ of the subjects declare that prices are important in their purchase decision depending on the 
emergency of the purchase, i.e. they can accept a higher price if they need the respective product immediately.

4. The position of the subjects towards the importance of prices in making the purchase decision in the case of non-food products.

More than half of the subjects $-59.25 \%$ ( $57.53 \%$ of men and $60.86 \%$ of women) state that for them the price is the essential element in making the purchase decision in the case of non-food products, $82.90 \%$ of the people aged 60 and more, i.e. pensioners, make the purchase decision especially in accordance with the level of the price. Moreover, it is very important that among the interviewed persons, not even one was found to declare that the price does not influence him or her in the decision to purchase these goods. We point out that $22.78 \%$ of the subjects declare that prices are important for their decision to buy the respective products, depending on the emergency of the purchase, i.e. they can accept a higher price if they need the respective product immediately, whereas $17.97 \%$ affirm that prices influence them only to a small extent.

5. The attitude of the subjects towards the importance of the tariffs of services in their purchasing decision.

More than three quarters of the persons interviewed $77.60 \%$ (80.98\% men and $74.45 \%$ women) declare that for them the price of the touristic package is important only in relation with the services (benefits) offered, this opinion being shared especially by people under 20 (85.44\%), i.e. pupils / students, with the mention that the other categories also exhibit very high percentages (over 67\%).

At the opposite pole, with the lowest weight $-1.07 \%$ ( $1.27 \%$ men and $0.89 \%$ women) we fund those who consider that the tariffs of touristic services influence them very little in the purchasing decision-making, even $0.00 \%$ in the case of those under 20 and over 60 , i.e. in the case of pupils / students and pensioners.

We must underline that rather many people (19.19\%) affirm that the tariffs represent the essential element in the case of touristic services, whereas $2.14 \%$ declare that they have other criteria in mind when they make the purchasing decision and not at all the price.

6 . The attitude of the subjects towards the price - quality ratio.

Most of the interviewed subjects - 65.98\% (68.78\% men and $63.37 \%$ women) consider that most of the times the price of products is mirrored in their quality, and this is the opinion of most people aged over 60, i.e. especially pensioners (77.72\%).

The lowest percentage $-0.53 \%(0.63 \%$ men and $0.44 \%$ women) is found among the persons who never consider that a more expensive product is also of a better quality $(0.00 \%$ for all people aged under 50), this idea being expressed unanimously by pupils / students, intellectuals, clerks, but also by those in the category of "other occupations".

We must point out that $23.32 \%$ always consider the more expensive products as having a higher quality, while $10.17 \%$ claim that the more expensive products rarely are of a better quality.

7. The manner in which the subjects assess the incomes that are currently at their disposal.

$45.57 \%$ (46.75\% men and $44.46 \%$ women) appreciate that the incomes at their disposal assure them a decent living, the highest percentages being registered in this case among the people under 20, i.e. in the case of pupils / students (60.13\%).

On the other hand, only $7.18 \%$ (11.41\% men and 3.25\% women) declared that their incomes allow them also to acquire certain more expensive goods, the lowest percentages being registered in this case too among those under 20 (0.95\%).

We point out that for $30.05 \%$ of the interviewed persons the incomes are sufficient only for the bare necessities, whereas for $17.20 \%$ of the subjects the incomes cannot provide them the minimum necessary products.
8. The manner in which the subjects will use a possible supplemental income.

Most of the interviewed persons - 37.23\% (29.16\% of men and $44.76 \%$ women) declared that if their income were to increase, they would spend most of this extra income for services, and this opinion is expressed mostly by those aged 5059 (46.15\%), while as regards the socio-professional category, the highest percentage is registered in the case of intellectuals (54.04\%).

The lowest percentages - 8.03\% (13.15\% men and 3.25\% women) were registered by those who declared that if their income increased, they would spend most of the extra income on food products, the lowest percentages being represented in this case by those aged between 20-29 (4.98\%), and as regards the socio-professional category, the lowest percentage is registered in the case of pupils / students (6.01\%).

9. Awareness of the income level of subjects ( 1 euro $=4.2$ lei).

Over half of them - 55.28\% (56.26\% men and 54.36\% women) have a net monthly income per family member between 500 and 700 lei, the highest percentages being registered among those aged 20 - 29 (68.16\%), and as regards the socio-professional category the highest percentage is exhibited by the clerks / office workers (63.45\%).

Only $20.87 \%$ of those interviewed $(20.76 \%$ men and $20.97 \%$ women) have a net monthly income per family member over 700 lei, the lowest percentage being found in this case among those under 20, i.e. especially the pupils / students (9.49\%). We point out that $23.85 \%$ of the subjects have a net monthly income per family member lower than 500 lei.

\section{CONCLUSION}

Based on the research performed, we found out that the Reşița's consumption pattern is still poor (the cultural and leisure consumption being way under-sized, as the other consumption needs also are not entirely satisfied), and the impact of prices and incomes on the consumption behaviour is very strong, irrespective of the nature of the household, with a plus in the case of the pensioners' households.

Keeping in mind the multiple interdependencies in an economy, the analysis of incomes and consumption prices may also have a higher role if we take into account the correlation with the manner in which other macroeconomic indicators have evolved, as there are close connections among the diverse stages of the application of economic reforms and the results obtained, reflected in the correlated evolution of the gross domestic product, inflation unemployment, wages raises etc.

In essence, we must understand that the improvement of consumption and in general the rise of the populations' living standard should be among the priorities of nowadays' scientific research and should represent the main preoccupation of the factors of power and decision.

\section{REFERENCES}

Cătoiu, I. (co-ordinator); Bălan C.; Popescu I. C.; Orzan G.; Vegheş C.; Dăneţiu T.; Vrânceanu D. (2002). Marketing researches, Uranus Editions, ISBN 978-973-7765-70-3, Bucharest

Cismaş L. (2004), Consumption in the economic theory, Mirton Editions, ISBN 973-661-472-7, Timişoara

Stanciu, M. (2006). Research methods of the consumption patterns. Economic studies and researches vol. 42, The Romanian Academy, pp. 7-15, INCE, CIDE

*** (2009) http://www.carasseverin.insse.ro - The CaraşSeverin County Statistics Division - Accessed on: 2010-0220

*** (2008) http://www.insse.ro - The National Statistics Institute, Statistics YearBook, Accessed on: 2010-02-15 